\title{
Black girls matter: A critical analysis of educational spaces and call for community-based programs
}

\author{
Natalie S. King ${ }^{1}$
}

Received: 4 September 2021 / Accepted: 24 January 2022 / Published online: 28 February 2022 This is a U.S. government work and not under copyright protection in the U.S.; foreign copyright protection may apply 2022

\begin{abstract}
This forum paper dialogues with Crystal Morton and Demetrice Smith-Mutegi's Making "it" matter: Developing African American girls and young women's mathematics and science identities through informal STEM learning. Their article unveils the experiences of participants in Girls STEM Institute, and how they challenged beliefs about their ability to perform in science and mathematics. I extend the discussion to explore the importance of access through community-based initiatives and stand on the premise that we will continue to oxygenate master narratives and perpetuate inequities if the structure and function of our programs fail to challenge the status quo. Therefore, this paper serves as a call to action to (1) recognize and address spirit murdering from teachers and authority figures who dismiss the abilities of Black girls to perform in STEM; (2) create humanizing spaces within schools and the larger community for Black girls to access STEM with authenticity; and (3) leverage the multidimensional identities of Black girls in ways that validate their cultural resources and brilliance. When we commit ourselves to creating more equitable learning spaces in STEM, then our actions will align with our responsibility to make Black girls matter.
\end{abstract}

Keywords Black girls · Identity · Informal learning $\cdot$ STEM $\cdot$ Community · Intersectionality

This review essay addresses issues raised in Crystal Morton and Demetrice Smith-Mutegi'paper entitled: Making "it" matter: developing African American girls and young women's mathematics and science identities through informal STEM learning (https://doi.org/10.1007/s11422-022-10105-8)

This manuscript is part of the special issue "Science education and the African Diaspora in the United States," guest edited by Mary M. Atwater and Jomo W. Mutegi.

Natalie S. King

natalieking@gsu.edu

1 College of Education and Human Development, Department of Middle and Secondary Education, Georgia State University, 30, Pryor St, Atlanta, GA 30301, USA 
Before I wasn't really confident in math or science and now after the camp, when I started school, I was kind of confident about it. I knew kind of what to expect, not in geometry but in science. It increased a lot in science. It increased in geometry as well but a lot in science after the camp. Veronica

This forum paper dialogues with Crystal Morton and Demetrice Smith-Mutegi's (2022) Making "it" matter: Developing African American girls and young women's mathematics and science identities through informal STEM learning. I shared an excerpt from Veronica, a participant in Girls STEM Institute (GSI) — the study's research context, whose self-efficacy in science and mathematics increased in response to her participation. Morton and Smith-Mutegi (2022) elevated the voices and experiences of Black girls in this informal STEM program. Their phenomenological study explored the essence of the girls' experiences in the institute, and how it shaped their self-efficacy in science and mathematics. This work is critical because programs such as GSI provide gateways for Black and Brown girls to enter into the STEM disciplines, and counternarratives that disrupt essentialist views about them being too loud (Fordham 1993), aggressive (Esposito and Edwards 2018; Morris 2007), confrontational (Evans-Winters and Esposito 2010), hypersexual (Esposito and Love 2008), and unintelligent unless they are "acting white" (Fordham and Ogbu 1986).

If we examine the culture of science and mathematics, negative narratives and stereotypes are even more pervasive and do not position girls of color as scientific or mathematical talent (Pringle et al. 2012), thus questioning their belongingness in STEM learning spaces (Olitsy et al. 2010). With increased initiatives and broadening participation efforts from the National Science Foundation (NSF) and other federal organizations, numbers have remained steady over the years for populations who are underrepresented in the STEM disciplines (NSF 2019). So, why aren't girls of color becoming women of color who pursue and persist in STEM careers? How can those obstructions be mitigated for a more promising future? The aforementioned questions are rooted in structural and systemic issues that require us to interrogate the white heteronormative nature of schools in America. With Black girls losing interest in science and mathematics at younger ages, unquestionably we must take a closer look at K-12 contexts within and beyond formal school settings.

Drawing on Morton and Smith-Mutegi's (2022) study and my work related to leveraging community-based programs to promote access and equity in STEM (King 2017; King and Pringle 2019), I center this paper around the following three themes-our need to (1) recognize and address spirit murdering from teachers and authority figures who dismiss the abilities of Black girls to perform in STEM; (2) create humanizing spaces within schools and the larger community for Black girls to access STEM with authenticity; and (3) leverage the multidimensional identities of Black girls in ways that validate their cultural resources and brilliance (Fig. 1).

\section{Recognize and address spirit murdering from teachers and authority figures who dismiss the abilities of Black girls to perform in STEM}

Morton and Smith-Mutegi (2022) opened their paper with a quote from Anissa who shared an experience about her advanced honors science teacher stating, "You do know no college is going to accept you." Anissa revealed that her teacher's words broke her spirit; she depended upon her grandmother, aunts, and mother to help her believe again. Unfortunately, these experiences are not novel to Anissa and happen far too often to Black and Brown girls across this nation. Spirit murdering is defined as the "disregard for those 
whose lives qualitatively depend on our regard" (Williams 1987, p. 73). Bettina Love (2019a) describes spirit murdering as a slow death steeped in racism whose intent is to reduce, humiliate, and ultimately destroy people of color. Spirit murdering takes on many forms within school contexts such as a denial of protection, inclusion, or acceptance due to structures of racism that induce trauma and rob Black girls, like Anissa, of their dignity and humanity (Love 2013; 2016). When their spirits are constantly under attack, it becomes increasingly difficult for them to learn.

Many teachers, administrators, and guidance counselors murder the spirits of Black girls every day without ever pulling a trigger. They injure Black girls through their perceptions, verbal utterances, and non-verbal body language. Even if the initial aim of their actions was not to cause harm, the unintended consequences of their underlying racial and gendered innuendos cannot be ignored. Hines and Wilmot (2018) argue for the spirit healing of Black girls from "antiblack aggressions," where we take a closer look at their experiences in social and educational spaces. In the case presented by Morton and SmithMutegi's (2022), Anissa sought healing and restoration from matriarchs in her family. Love (2019b) refers to this as the educational survival complex, which is exhausting because Black girls and their families are forced to navigate antidark spaces where their bodies, spirits, and being do not matter. We must seek spirit healing for Black girls, which can only take place by first acknowledging the (un)intended trauma, attending to their physical and mental wellbeing, and then seeking to protect and accept them, in lieu of control tactics and rejection.

To truly recognize and overcome the spirit murdering of our most vulnerable populations, we must complicate race relations in schools and the greater American society writ large. Rosa (2018) purports that the science education community cannot ignore and deny the impact of racism, which requires the use of intersectional approaches to inform our conceptions about STEM identity development. Stinson, Jett, and Williams (2013) call to examine our uses and misuses of school mathematics and how we can disrupt mathematics as a White institutional space. Through critical lenses and transdisciplinary approaches, we can interrogate the racialized and gendered science and mathematical experiences of Black girls in educational spaces.

The vignettes shared by Morton and Smith-Mutegi (2022) brilliantly display examples of when Black girls' abilities in science and mathematics were dismissed. These kind of negative messages from teachers not only induce spirit murdering, but also have tangible outcomes that result in their underrepresentation in the STEM disciplines. Research suggests that Black girls who are high-achieving are typically disadvantaged by their teachers and school counselors who underestimate their potential and do not have high expectations for their academic success (Brickhouse et al. 2000; Brickhouse and Potter 2001). They rarely recommend Black girls for advanced courses and magnet programs, which result in them consistently being tracked into lower-level courses (Walker 2007). In these lower-tracked courses, classroom instruction typically emphasizes numeracy, literacy, test preparation activities, and decontextualized skills (King and Pringle 2019; Lomax et al. 1995; Tate 2001). Therefore, even if Black girls are interested in the STEM disciplines, and do well in their coursework, many are unable to compete with their White counterparts due to opportunity gaps (Carter and Welner, 2013; Ladson-Billings 2013; Milner 2010). Additional research reveals that Black girls are unfairly marginalized due to Discourses that only positively recognize those who are quiet, polite, passive, and fast workers (WadeJaimes and Schwartz 2019). Black girls are also targets of microaggression (Parsons et al. 2018), dysconscious racism (King 2015), and overdisciplining (Love, 2019b) in formal school settings. We can no longer afford to ignore the inherent racialized and gendered 
stereotypes that inform teachers' decisions to overlook the science and mathematical abilities of Black girls (Else-Quest et al. 2013; Joseph et al. 2016). This leads to the next theme focused on humanizing STEM learning spaces and reconceptualizing the types of experiences that Black girls are afforded.

\section{Create humanizing spaces within schools and the larger community for Black girls to access STEM with authenticity}

Morton and Smith-Mutegi (2022) discussed disparities in the types of learning experiences that Black girls are afforded, and advocated for transformative spaces where their abilities and belongingness in STEM are validated. In their argument, they centered the importance of self-efficacy (Bandura 1986; Britner and Pajares 2006) and teaching the STEM disciplines using socially transformative curricula to master content, currency, context, critique, and conduct (Mutegi 2011). William Tate (2001) argued that access to science and mathematics education in urban schools is a civil rights issue, and that inequalities in schooling have focused on sharing the same "educational space" with our White counterparts, rather than on access to high-quality academic preparation. Our misguided energies within an American racialized society have produced inequitable opportunities for children of color to learn in transformative and culturally sustaining ways. Therefore, school science and mathematics is a social justice issue that requires us to rethink our spaces beyond the confines of formal schools to community-based and presumably more humanizing spaces.

Whiteness and Eurocentric ideals infiltrate the school curriculum and the ways in which science and mathematics are taught. We can leverage community-based spaces to incorporate and celebrate Afrocentric pedagogies, philosophies, and epistemologies for more authentic ways of learning that embrace students' cultures and lived experiences. Programs like Girls STEM Institute are critical for Black girls to build self-confidence and connectedness in STEM, while also maintaining their cultural competence. These spaces reposition Black girls as problem solvers rather than the source of the problem.

In previous articles, I shared the experiences of 4th-8th grade Black girls who participated in I AM STEM Camp-a comprehensive enrichment summer program for which I am the founder and executive director. In I AM STEM, we seek to develop culturally healthy students by meeting the needs of the whole child: mind, body, and spirit (King 2017; Ladson-Billings 1989). In reflecting on their STEM learning experiences, Black girls revealed that teachers who promoted their academic success formed positive relationships with their parents, were responsive to their needs, and encouraged critical and creative thinking (King 2017). To gain an understanding of Black girls' STEM learning experiences across contexts, we documented the ways in which they translated their informal learning experiences into practice within their formal schools. When provided with equitable opportunities to learn, Black girls became agentic to continue their engagement in STEM activities throughout the school year. They identified field trips and engagement with authentic science phenomena as critical components to igniting interests in STEM (King and Pringle 2019).

Unfortunately, many outreach programs are not specially designed with girls of color in mind. Therefore, programs like Girls STEM Institute and I AM STEM are critical to moving the needle and changing the trajectory of Black girls and women in STEM. In order to offer more humanizing spaces, we must create programs where they are engaged in rigorous and relevant curriculum, and the organizers and instructors believe in and nurture their brilliance. We will continue to oxygenate master narratives and perpetuate inequities if the structure and function of our programs fail to challenge the status quo. Therefore, our 
conceptions of community-based programs should emphasize enrichment, validation, and whole-child development rather than remediation, credit restoration, and test preparation. It is our obligation to create transformative spaces for positive STEM identity development and increased self-efficacy.

\section{Leverage the multidimensional identities of Black girls in ways that validate their cultural resources and brilliance.}

In this final theme, I applaud Crystal Morton and Demetrice Smith-Mutegi's efforts to organize and implement Girls STEM Institute, and call for a close examination of the complex identities of Black girls. Morton and Smith-Mutegi (2022) understand the importance of Black women scholars leveraging their resources to create community-based outreach programs that embrace Black girls' multidimensional identities. They incorporated STEM professionals who shared the same race and biological sex as the camp participants, thus emphasizing the need for Black girls to see Black women who are excelling in STEM careers so they can project themselves into that image (Britner and Pajares 2006; King and Pringle 2019). Simply put, representation matters! A synthesis of research examining the intersectional experiences of Black women and girls in STEM education revealed that Black girls have distinct experiences due to their social identities, psychological processes, and educational outcomes (Ireland et al. 2018). This review discovered that many studies have not acknowledged the key psychological processes associated with identity nor the simultaneous racialized and gendered experiences in STEM educational settings.

To address these gaps in the literature, my colleague and I developed a conceptual framework exploring the Multidimensionality of Black Girls' STEM Learning (King and Pringle, 2019). It acknowledges the complex interactions of their perceived identities within and across educational contexts by connecting Solorzano, Ceja, and Yosso's (2000) counterspaces with Wing's (1997) critical race feminism (CRF).

CRF focuses on the lived experiences of those who face multiple discrimination based on race, gender, and class, and how those factors intersect in complex ways within a system of White male patriarchy and racist oppression (Wing 1997). CRF is a multidisciplinary approach that emphasizes both theory and practice and encourages action on micro and

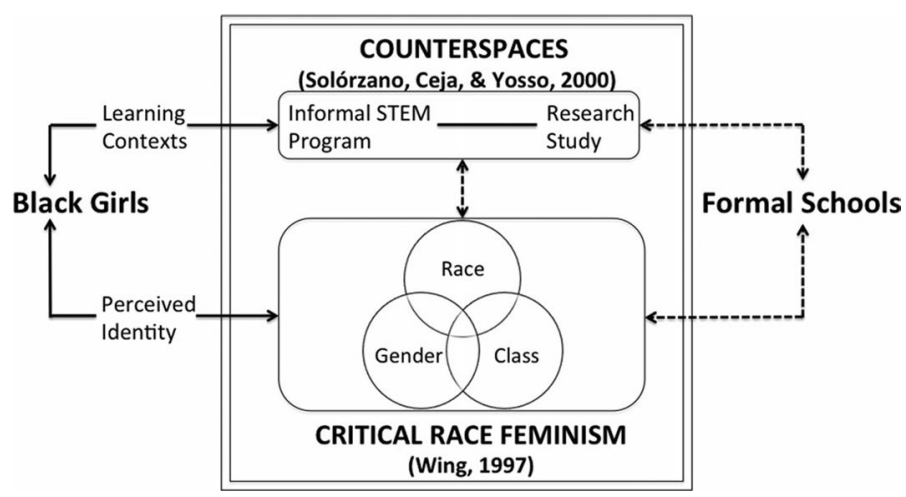

Fig. 1 Multidimensionality of Black Girls' STEM Learning: A Conceptual Framework 
macro levels to improve the plight of Black women and girls. Counterspaces are places where deficit notions of people of color can be challenged and replaced with a positive and affirming climate. These spaces can be physical, conceptual, or ideological and are fostered through positive support systems, which include family, friends, community members, and organizations. Counterspaces provide opportunities for Black girls to problematize deficit notions, establish and maintain relationships, and validate each other's experiences as important knowledge (Solórzano et al. 2000; Solórzano and Villalpando 1998).

Four Black middle and high school girls who participated in GSI described the enrichment program as a place of comfort where they felt safe taking risks and being their authentic selves. Participants' accounts provided more nuanced understandings about safety and comfort. In designing programs, organizers should note that Black girls appreciate environments where they can try and fail, answer and be incorrect, and provide naïve solutions to problems as they work toward more sophisticated understandings. In these spaces, they can ask for help, clarification, and additional time to process without their intelligence being misinterpreted or misjudged. Furthermore, many Black girls value collaboration and fostering a community of learners over competition.

Utilizing the Multidimensionality of Black Girls' STEM Learning conceptual framework as a lens to respond to the study, GSI served as a counterspace. Participants discussed the transferability of the science and mathematics skills learned during the institute to their formal school curriculum and attributed their increased confidence to the rich experiences that were afforded. Activities like the financial simulation and seed dissections provided access to science and mathematics concepts that were applicable to their lives. The authors' careful and intentional design of the institute (inclusive of socially transformative STEM curriculum), and the girls' rich depictions of its impact on their self-efficacy, confidence, and overall identities, made GSI a counterspace. Morton and Smith-Mutegi (2022) leveraged their social capital by connecting content to Black girls' interests and cultures so that the curriculum was rigorous and relevant. They related to the girls, were embedded in their community, and shared similar aspects of their identities.

Other scholars have used intersectional approaches to amplify and document the stories of Black children in informal contexts. For example, Mark (2018) employed an intersectional lens to conduct a longitudinal case study exploring the experiences of a Black male who engaged in a community-based STEM program focused on social justice and its impact on his STEM identity development. Gholdy Muhammad (2014) discussed the benefits of a summer writing collaborative that she developed specifically for Black adolescent girls to understand their “....self-identity among dominant narratives that attempt to 'write' Black girls realities" (p. 323). Her present-day literary society provided a counterspace for Black girls to negotiate, mediate, and construct their identities. These spaces often serve as a mechanism to validate the cultural resources and brilliance of Black children in ways that traditional schools do not. This is consistent with recommendations from Lemons-Smith (2013) who states that Black children bring personal and intellectual capital from out-ofschool programs that must be leveraged in formal school settings.

\section{Final thoughts}

Morton and Smith-Mutegi (2022) titled their paper "Making 'it' matter." In this continued dialogue, I highlight our urgency to make "Black girls matter" in STEM education. In science education specifically, we often elevate content over context, and being correct over 
being morally just. This paper is a call to humanize science by prioritizing mattering over matter. When we teach the fundamental principles of our discipline, children are required to learn that "matter" is anything that has mass and takes up space. This concept informs every branch of science with implications ranging from the particulate to astronomical aspects of our field. What if we reconceptualized the construct of matter in STEM learning spaces to include the wellbeing of all children? Love (2019b) described mattering as a quest for humanity, an internal desire for freedom, joy, and restorative justice. We must transform science and mathematics learning spaces so that Black girls can experience spirit healing in lieu of spirit murdering, humanizing educational experiences over those that are oppressive, and their multidimensional identities being validated rather than critiqued and ignored.

Previously, I discussed the importance of familial matriarchs who assist Black girls to heal from spirit murdering to survive, persist, and maintain their overall sanity in STEM learning spaces-spaces that are often violent and unwelcoming. We must extend their village to include community matriarchs and othermothers who will assume a sense of responsibility to love and nurture Black girls as if they were their own biological children (Case 1997; Foster 1993). May we carefully consider the roles that we choose to play and serve as mentors, teachers, coconspirators, listeners, role models, and friends. I close this paper with another quote from Veronica who stated, “...I used to think I wasn't beautiful. The camp kind of showed me that you are beautiful in your own way." When we create more equitable spaces for Black girls in STEM, they will begin to internalize their beauty and realize that not only do they belong here, but they also matter!

Open Access This article is licensed under a Creative Commons Attribution 4.0 International License, which permits use, sharing, adaptation, distribution and reproduction in any medium or format, as long as you give appropriate credit to the original author(s) and the source, provide a link to the Creative Commons licence, and indicate if changes were made. The images or other third party material in this article are included in the article's Creative Commons licence, unless indicated otherwise in a credit line to the material. If material is not included in the article's Creative Commons licence and your intended use is not permitted by statutory regulation or exceeds the permitted use, you will need to obtain permission directly from the copyright holder. To view a copy of this licence, visit http://creativecommons.org/licenses/by/4.0/.

\section{References}

Bandura, A. (1986). The explanatory and predictive scope of self-efficacy theory. Journal of social and clinical psychology, 4(3), 359-373.

Brickhouse, N. W., Lowery, P., \& Schultz, K. (2000). What kind of a girl does science? The construction of school science identities. Journal of Research in Science Teaching, 37, 441-458.

Brickhouse, N. W., \& Potter, J. T. (2001). Young women's scientific identity formation in an urban context. Journal of Research in Science Teaching, 38, 965-980.

Britner, S. L., \& Pajares, F. (2006). Sources of science self-efficacy beliefs of middle school students. Journal of Research in Science Teaching: The Official Journal of the National Association for Research in Science Teaching, 43(5), 485-499.

Carter, P. L., \& Welner, K. G. (Eds.). (2013). Closing the opportunity gap: What America must do to give every child an even chance. Oxford University Press

Case, K. I. (1997). African American othermothering in the urban elementary school. The Urban Review, 29(1), 25-39.

Else-Quest, N. M., Mineo, C. C., \& Higgins, A. (2013). Math and science attitudes and achievement at the intersection of gender and ethnicity. Psychology of Women Quarterly, 37(3), 293-309.

Esposito, J., \& Edwards, E. B. (2018). When Black girls fight: Interrogating, interrupting, and (re) imagining dangerous scripts of femininity in urban classrooms. Education and urban society, 50(1), 87-107. 
Esposito, J., \& Love, B. (2008). More than a video hoe: Hip hop as a site of sex education about girls' sexual desires. The corporate assault on youth: Commercialism, exploitation, and the end of innocence, 43-82.

Evans-Winters, V. E., \& Esposito, J. (2010). Other people's daughters: Critical race feminism and Black girls' education. The Journal of Educational Foundations, 24(1/2), 11.

Fordham, S. (1993). "Those loud Black girls":(Black) women, silence, and gender "passing" in the academy. Anthropology \& Education Quarterly, 24(1), 3-32.

Fordham, S., \& Ogbu, J. U. (1986). Black students' school success: Coping with the "burden of 'acting white." The urban review, 18(3), 176-206.

Foster, M. L. (1993). Othermothers: Exploring the educational philosophy of Black American women teachers. Feminism and social justice in education: International perspectives, 101-123.

Hines, D. E., \& Wilmot, J. M. (2018). From spirit-murdering to spirit-healing: Addressing anti-black aggressions and the inhumane discipline of Black children. Multicultural Perspectives, 20(2), 62-69.

Ireland, D. T., Freeman, K. E., Winston-Proctor, C. E., DeLaine, K. D., McDonald Lowe, S., \& Woodson, K. M. (2018). (Un)hidden figures: A synthesis of research examining the intersectional experiences of black women and girls in STEM education. Review of Research in Education, 42(1), 226-254.

Joseph, N. M., Viesca, K. M., \& Bianco, M. (2016). Black female adolescents and racism in schools: Experiences in a colorblind society. The High School Journal, 100(1), 4-25.

King, J. E. (2015). Dysconscious racism: Ideology, identity, and the miseducation of teachers. In Dysconscious Racism, Afrocentric Praxis, and Education for Human Freedom: Through the Years I Keep on Toiling (pp. 125-139). Routledge.

King, N. S. (2017). When teachers get it right: Voices of black girls' informal STEM learning experiences. Journal of Multicultural Affairs, 2(1), 5.

King, N. S., \& Pringle, R. M. (2019). Black girls speak STEM: Counterstories of informal and formal learning experiences. Journal of Research in Science Teaching, 56(5), 539-569.

Ladson-Billings, G. (1989). A tale of two teachers: Exemplars of successful pedagogy for Black students. Paper presented at the Educational Equality Project Colloquium, New York, NY.

Ladson-Billings, G. (2013). Lack of achievement or loss of opportunity. Closing the opportunity gap: What America must do to give every child an even chance, 11 .

Lemons-Smith, S. (2013). Tapping into the intellectual capital of Black children in mathematics: Examining the practices of pre-service elementary teachers. In J. Leonard \& D. B. Martin (Eds.), The brilliance of Black children in mathematics: Beyond the numbers and toward new discourse (pp. 323-339). Information Age Publishing.

Lomax, R. G., West, M. M., Harmon, M. C., Viator, K. A., \& Madaus, G. F. (1995). The impact of mandated standardized testing on minority students. Journal of Negro Education, 171-185.

Love, B. L. (2013). "I see Trayvon Martin”: What teachers can learn from the tragic death of a young black male. The Urban Review, 45(3), 1-15.

Love, B. L. (2016). Anti-Black state violence, classroom edition: The spirit murdering of Black children. Journal of Curriculum and Pedagogy, 13(1), 22-25.

Love, B. L. (2019). The spirit murdering of Black and Brown children. Education Week, 38(35), 18-19.

Love, B. L. (2019b). We want to do more than survive: Abolitionist teaching and the pursuit of educational freedom. Beacon Press.

Mark, S. L. (2018). A bit of both science and economics: A non-traditional STEM identity narrative. Cultural Studies of Science Education, 13(4), 983-1003.

Milner, H. R. (2010). Start where you are, but don't stay there. Harvard.

Morris, E. W. (2007). "Ladies" or "loudies"? perceptions and experiences of Black girls in classrooms. Youth \& Society, 38(4), 490-515.

Morton C. \& Smith-Mutegi (D) (2022). Making "it" matter: Developing African American girls and young women's mathematics and science identities through informal STEM learning. Cultural Studies of Science Education, 1-20.

Muhammad, G. G. (2014). Focus on Middle School: Black Girls Write!: Literary Benefits of a Summer Writing Collaborative Grounded in History: Detra Price-Dennis. Editor. Childhood Education, 90(4), 323-326.

Mutegi, J. W. (2011). The inadequacies of "Science for All" and the necessity and nature of a socially transformative curriculum approach for African American science education. Journal of Research in Science Teaching, 48(3), 301-316.

National Science Foundation, National Center for Science and Engineering Statistics. (2019). Women, Minorities, and Persons with Disabilities in Science and Engineering: 2019. Special Report NSF 19-304. Alexandria, VA. Available at https://ncses.nsf.gov/pubs/nsf19304/ 
Olitsky, S., Flohr, L. L., Gardner, J., \& Billups, M. (2010). Coherence, contradiction, and the development of school science identities. Journal of Research in Science Teaching, 47(10), 1209-1228.

Parsons, E. R., Bulls, D. L., Freeman, T. B., Butler, M. B., \& Atwater, M. M. (2018). General experiences+ race + racism $=$ Work lives of Black faculty in postsecondary science education. Cultural Studies of Science Education, 13(2), 371-394.

Pringle, R. M., Brkich, K. M., Adams, T. L., West-Olatunii, C., \& Archer, D. A. B. (2012). Factors influencing elementary teachers' Positioning of African American girls as science and mathematics learners. School Science and Mathematics, 112(4), 217-229.

Rosa, K. (2018). Science identity possibilities: A look into Blackness, masculinities, and economic power relations. Cultural Studies of Science Education, 13(4), 1005-1013.

Solórzano, D. G., \& Villalpando, O. (1998). Critical race theory, marginality, and the experience of students of color in higher education. Sociology of Education: Emerging Perspectives, 21, 211-222.

Solórzano, D., Ceja, M., \& Yosso, T. (2000). Critical race theory, racial microaggressions, and campus racial climate: The experiences of African American college students. Journal of Negro Education, 60-73.

Stinson, D. W., Jett, C. C., \& Williams, B. A. (2013). Counterstories from mathematically successful African American male students: Implications for mathematics teachers and teacher educators. The brilliance of Black children in mathematics: Beyond the numbers and toward new discourse, 221-245.

Tate, W. (2001). Science education as a civil right: Urban schools and opportunity-to-learn considerations. Journal of Research in Science Teaching: The Official Journal of the National Association for Research in Science Teaching, 38(9), 1015-1028.

Wade-Jaimes, K., \& Schwartz, R. (2019). "I don't think it's science:” African American girls and the figured world of school science. Journal of Research in Science Teaching, 56(6), 679-706.

Walker, E. N. (2007). Why aren't more minorities taking advanced math? Educational Leadership, 65(3), 48.

Williams, P. (1987). Spirit-murdering the messenger: The discourse of fingerpointing as the law's response to racism. U. Miami L. Rev., 42, 127.

Wing, A. K. (1997). Critical race feminism: A reader. New York University Press.

Publisher's Note Springer Nature remains neutral with regard to jurisdictional claims in published maps and institutional affiliations.

Natalie S. King is an assistant professor of science education at Georgia State University. Her scholarly work focuses on advancing Black girls in STEM education, community-based youth programs, and the role of curriculum in fostering equity in science teaching and learning. Dr. King is the founder of I AM STEM Camps whose vision is to transform the face of STEM one community at a time. Her recent publications related to this work are in the Journal of Research in Science Teaching, Science Education, and the Journal of Multicultural Affairs. 